\title{
Efeito de nucleosídio trifosfato eritrocítico no equilibrio de oxigênio de hemoglobinas completas e fracionadas de Hypostomus e Pterygoplichthys, bagres aeróbicos facultativos (
}

\author{
Roy E. Weber (') \\ Stephen C. Wood ( ${ }^{2}$ )
}

\section{Resumo}

São estudados o equilíbrio de oxigênio de hemoglobinas de Hypostomus e Pterygoplichthys e suas sensibilidades ao nucleosídio trifosfatos eritrocítico (NTP), ATP e guanosina trifosfato (GTP) pa. ra investigar o mecanismo pelo qual o sangue se adapta à respiração aérea e aquática. As hemoglobinas de ambas as espécies são heterogêneas. Todas as frações hemoglobínicas isoladas por focalizaçäo isoelétrica, revelaram uma alta sensibilidade a NTP, mas a GTP decresce a afinidade de $\mathrm{O}_{2}$ cerca de duas vezes tão efetivamente quanto a ATP. Foi encontrado um componente hemoglobínico catódico com um efeito Bohr revertido em Pterygoplichthys mas não em Hypostomus. Os dados são discutidos em relação à modulação do cofator in vivo, de afinidade pelo $\mathrm{O}_{2}$ do sangue e a importância adaptativa da heterogeneidade funcional de hemoglobinas de peixes.

\section{INTRODUÇÃo}

Hypostomus e Pterygoplichthys são bagres inativos, habitantes de leito e encouraçados, encontrados no rio Amazonas, sendo capazes de respiração bimodal. Enquanto eles extraem oxigênio com as guelras em águas bem oxigenadas (monóxica), engolem o ar quando a água é hipóxica, usando o trato intestinal com órgão para as trocas gasosas.

Apesar de aeróbico a baixo $\mathrm{O}_{2}$ na água, a afinidade pelo oxigênio do sangue de Hypostomus é mais alta quando o peixe está em agua hipóxica do que em normóxica. A aumentada afinidade pelo oxigênio parece ser adaptativa a tensões internas de $\mathrm{O}_{2}$ baixa, as tensões de oxigênio internas em proporção ao tempo sob hipóxica, são causada por uma diminuída interação com os cofatores alostéricos dos glóbu- los vermelhos. Em Hypostomus e Pterygoplichthys, a aclimatação hipóxica é acompanhada por um marcante decréscimo nas concentrações dos nucleosídios trifosfatos (NTP), particularmente guanosina trifosfato (GTP) (Weber et al., 1978). Embora a retenção de $\mathrm{CO}_{2}$ ocorra durante a respiração aeróbica na água hipóxica, um aumento de bicarbonato no plasma prevê um decréscimo no $\mathrm{pH}$ sangüíneo, o qual, a miúdo aumenta a afinidade oxigênio associada a uma queda no GTP eritrocítico (Wood et al., 1978).

Este artigo focaliza as propriedades de união de oxigênio e sensibilidade aos fosfatos eritrócíticos de hemoglobinas livres de cofatores, dos bagres encouraçado, Hypostomus e Pterygoplichthy com o objetivo de elucidar, os mecanismos pelos quais todo o sangue responde aos níveis de oxigênio da água e ao modo de respiração. Ademais, as implicações de multiplicidade da hemoglobina a esta adaptação é investigada por medida de $\mathrm{pH}$ e sensibilidade de cofatores das frações de hemoglobina isoladas. Tais dados são de interesse comparativo adicional com respeito a possiveis relações entre multiplicidade da hemoglobina e habitat do peixe. Isto sustenta a hipótese (Hashimoto et al., 1960; Powers, 1972 Powers \& Edmundson, 1972) de que a ocorrência de componentes hemoglobínicos catódicos com afinidade por oxigênio alta e $\mathrm{pH}$ - insensibilidade ao $\mathrm{pH}$ no peixe, são adaptativos ao transporte de oxigênio sob condições de baixa tensão de oxigênio ou $\mathrm{pH}$ interno, quando os componentes anódicos sensíveis ao $\mathrm{pH}$ estão incapacitados para carregar o $\mathrm{O}_{2}$. Hypostomus e Pterygoplichthys são bagres intimamente relacionados, de hábitos e habitat similares.

( ') - Versão original inglesa publicada em Comp. Biochem Physiol. vol. 62 A (1). 1979.

(1) - Department of Zoophysiology of Aarhus, DK-8000 Aarhus C.., Denmark.

(2) - Department of Physiol, University of New Mexico, Albuquerque, New Mexico 87131, U.S.A. 
Entretanto, enquanto ambas as espécies mostram polimorfismo em heterogeneidade hemoglobínica, apenas Pterygoplichthys parece conter quantidades significativas de hemoglobinas (catódicas) eletroforeticamente lentas (Fyhn et al., 1978). Isto sugere que Hypostomus e Pterygoplichthys são candidatos promissores para atestar as argumentações acima sobre a importância adaptativa de hemoglobinas catódicas no peixe.

\section{MATERIAL E MÉTODOS}

Os Hypostomus e Pterygoplichthys foram coletados no rio Amazonas, próximo ao lago do Janauacá, cerca de $150 \mathrm{~km}$ a oeste de Manaus, Brasil. Para prevenir heterogeneidade de amostras associada com polimorfismo hemoglobínico nestes peixes (Fyhn et al., 1978), todos os presentes dados referem-se à hemoglobina de um espécime de cada espécie (pesando cerca de 850 e $300 \mathrm{~g}$, respectivamente). Baseado na heterogeneidade hemoglobínica, os Hypostomus usados correspondem ao fenótipo $\mathrm{V}$, e os Pterygoplichthys ao fenótipo I (Fyhn et al., 1978).

As amostras de sangue foram coletadas por punção cardíaca usando seringas heparinizadas. Os glóbulos vermelhos foram lavados 3 vezes em $\mathrm{NaCl}$ a $1,5 \%$ contendo Tris $10^{-2} \mathrm{~m}$, $\mathrm{pH} 7,4$, empacotados por centrifugação e congelado por 2-4 semanas, após conversão da hemoglobina a carboxi derivado (ex., o estado no qual o padrão eletroforético de hemoglobina de truta é mais estável durante estocagem em congelador - Reinitz, 1976). A hemoglobina em solução foi preparada por mistura de 2-3 volumes de água com 1 volume de glóbulos vermelhos e precipitando os fragmentos celulares por centrifugação. Todos os processos preparativos foram conduzidos a $0-5^{\circ} \mathrm{C}$.

As hemoglobinas foram fracionadas por passagem através de troca iônica em Amberlite MB-3. As amostras foram reduzidas por adição de ditionito de sódio sólido e dialisadas contra 3 trocas de tampão Tris $10^{-2} \mathrm{M}, \mathrm{pH} 7,5$, contendo $5 \times 10^{-4}$ EDTA por 48 horas. A hemoglobina fol concentrada usando concentradores Amicon B15 (Oosterhout, Holland), e as concentrações "foram medidas espectrofotometricamente. $\mathrm{O}$ equilíbrio de $\mathrm{O}_{2}$ foi medido por uma técnica de câmara de difusão, modificada segundo Niesel e Thews (1961). Valores de $P_{50}$ e $n_{50}$ (expressando a tensão de oxigênio e o coeficiente de cooperatividade de Hill da hemoglobina a meia saturação) foram interpoladas por ploteado logarítmico linearizado dos dados de equilíbrio de $\mathrm{O}_{2}$. Os efeitos de ATP e GTP foram medidos por adição à soluções de hemoglobina fracionada de volumes apropriados de soluções de concentrações conhecidas, dos sais dissodícos dos nucleosídios trifosfatos (ensaiados usando testes químicos da Sigma) .

As hemoglobinas foram separadas por focalização isoelétrica em uma coıuna preparativa de $110 \mathrm{ml} \mathrm{LKB}$, a $5^{\circ} \mathrm{C}$ usando uma mistura de anfolinas LKB de pH 5 a 8 e 3 a $10(0,5$ e $0.2 \%$ respectivamente). $\mathrm{Na}$ estabilização o conteúdo da coluna foi fracionada em amostras de $1,6 \mathrm{ml}$ para medidas de D.O. a $540 \mathrm{~nm}$ e $\mathrm{pH}$ a $5^{\circ} \mathrm{C}$. As frações de hemoglobina recuperadas da focalização isoelétrica foram dialisadas por 48 horas contra diversas trocas de Tris-EDTA anterior às medidas de equilíbrio de $\mathrm{O}_{2}$.

\section{RESULTADOS}

As afinidades por oxigênio e valores de $n$ e suas dependências de $\mathrm{pH}$ dos hemolisados fracionado de Hypostomus e Pterygoplichthys são dados nas Figs. 1 e 2 (curvas sólidas). As hemoglobinas de ambas as espécies mostram distintos efeitos Bohr alcalinos - a pH 7,0, os valores $\phi\left(\Delta \log \mathrm{P}_{50} / \Delta \mathrm{pH}\right)$ são cerca de $-0,34$ e $-0,46$, respectivamente. $\mathrm{A} \mathrm{pH}$ mais alto, os efeitos Bohr são, entretanto, reduzidos e revertidos (tornando-se cerca de $+0,04$ e $+0,14$, respectivamente, a $\mathrm{pH} 8,0$ ). As hemoglobinas fracionadas de ambas as espécies mostram fraca cooperatividade na ligação $\mathrm{O}_{2}(n=1,2$ a 1,5 ) .

Os efeitos dos principais nucleosídios trifosfato eritrocíticos ATP e GTP, são mostrados nas Fig. $3 \mathrm{~A}$ e $\mathrm{B}$. A afinidade das hemoglobinas por $\mathrm{O}_{2}$, de ambas as espécies, é marcadamente decrescida por cada fosfato mas a tensão de $\mathrm{O}_{2}$ de meia-saturação aumenta cerca de 2 vezes mais na presença de GTP, como o faz com ATP à mesma concentração. Os cofatores aumentam o coeficiente de cooperatividade $n$, mas este efeito é mais marcado em Hypostomus do que em Pterygoplichthys. 


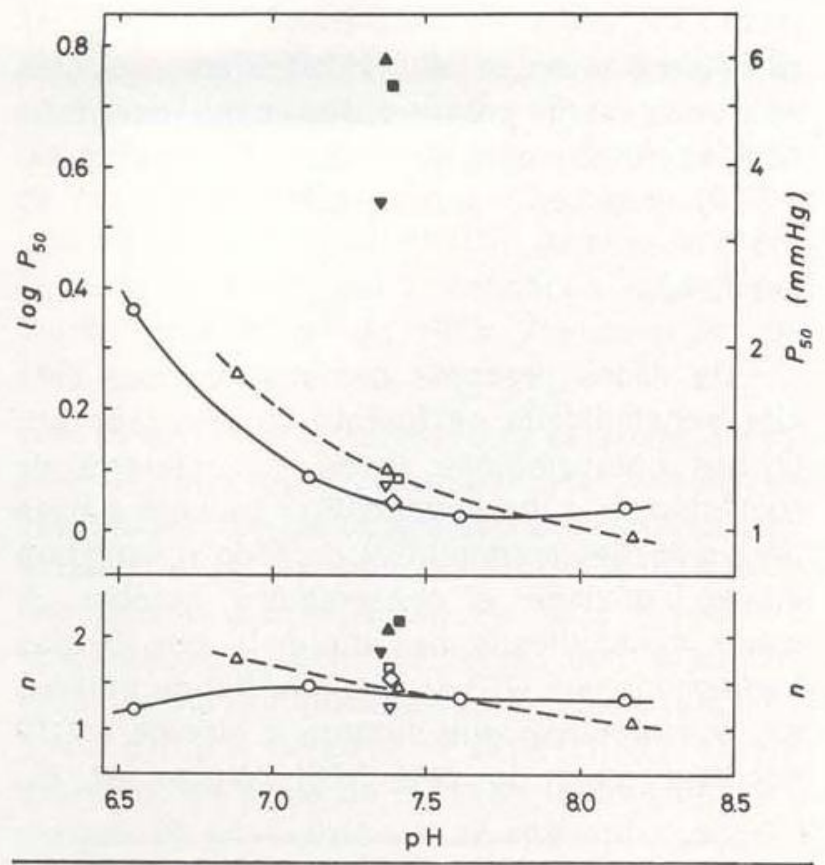

Fig. 1 - Efeitos de pH e GTP sobre a tensão de oxigênio à meia-saturação, $\mathrm{P}_{50}$ e coeficientes de cooperatividade de Hill $\mathbf{n}$ de hemoglobinas de Hypostomus, medidos em tampōes Tris e Bis Tris, $I=0.05$ a $25^{\circ} \mathrm{C}$, hemolisado fracionado, $0,15 \mathrm{mM} \mathrm{Hb}$ (base tetrâmera); $\Delta, \boldsymbol{\Delta}$, componente hemoglobínico I; $\square$, componente II; $\nabla, \boldsymbol{\nabla}$, componente III (cf. Fig. 4A) todos a concentrações de $0,05 \mathrm{mM}$; $\diamond$, componentes I+II+III, concorrendo às suas concentrações relativas aproximadas in vivo $(74,18$ e $8 \%$, respectivamente, de hemoglobina total). Símbolos abertos - hemoglobinas fracionadas; símbolos fechados, hemoglobinas fracionadas adicionadas de GTP (excesso molar de cerca de 8 vezes sobre a $\mathrm{Hb}$ tetrâmera).

As fig. 4A e B mostram a separação dos componentes de hemoglobina de cada espécie por focalização isoelétrica. A hemoglobina de Hypostomus é resolvida em 3 frações principais. Os carboxiderivados destas frações foram isoeletricamente próximos de $7,4,6,7$ e 6,0 a $5^{\circ} \mathrm{C}$, e suas abundâncias relativas decresceram com o decréscimo dos pontos isoelétricos (cerca de 72,17 e $7 \%$ do heme total, respectivamente). Além disso 2 componentes menores (cada um correspondendo a menos de $2 \%$ do heme total) foram focalizados perto de $\mathrm{pH} 8$ e 5,7 (Fig. 4A). A hemoglobina de Pterygoplichthys exibiu alto grau de heterogeneidade de carga, resolvendo em 5 componentes principais com valores de pl próximos de $8,7,7,9,7,2,6,9$ e 6,4 , e uns poucos compo- nentes pequenos (valores de $\mathrm{pl}$ em torno de 7,6 e 5,6 ). Para os experimentos de equilibrio de $\mathrm{O}_{2}$ duas frações foram preparadas, contendo os mais abundantes componentes de hemoglobina catódico e anódico respectivamente ( $a$ e $b$ na Fig. 4B) .

O componente de hemoglobina mais abundante (I) de Hypostomus tem afinidade por $\mathrm{O}_{2}$ similar e do hemolisado mas com um efeito Bohr levemente maior do que o hemolisado total (Fig. 1), indicando a presença de uma mais baixa sensibilidade de $\mathrm{pH}$ nos outros componentes na ausência de interações mútuas. Cada um dos 3 principais componentes mostrou uma alta sensibilidade de seus valores $\mathrm{P}_{50}$ à presença de GTP próximo a $\mathrm{pH} 7,4$ (Fig. 1).

Em Pterygoplichthys os dois grupos de componentes estudados funcionalmente ( $a$ e $b$ na Fig. 4 B) demonstraram propriedades de equilibrio de $\mathrm{O}_{2}$ divergentes. Em contraste a um marcado efeito Bohr nos componentes anódicos (b), as hemoglobinas catódicas têm um leve efeito Bohr revertido $\phi=-0,53 \mathrm{e}+$ $0,08$, respectivamente, a $\mathrm{pH} 7,0)$. Tendo em mente as diferenças de concentração, a Fig. 1 mostra que a afinidade por $\mathrm{O}_{2}$ e sua sensibilidade de $\mathrm{pH}$ do hemolisado em média aproximadamente aquelas das frações separadas, indicando a ausência de uma interação funcionalmente significativa entre estes. Ambas as frações exibem a mesma sensibilidade a ATP

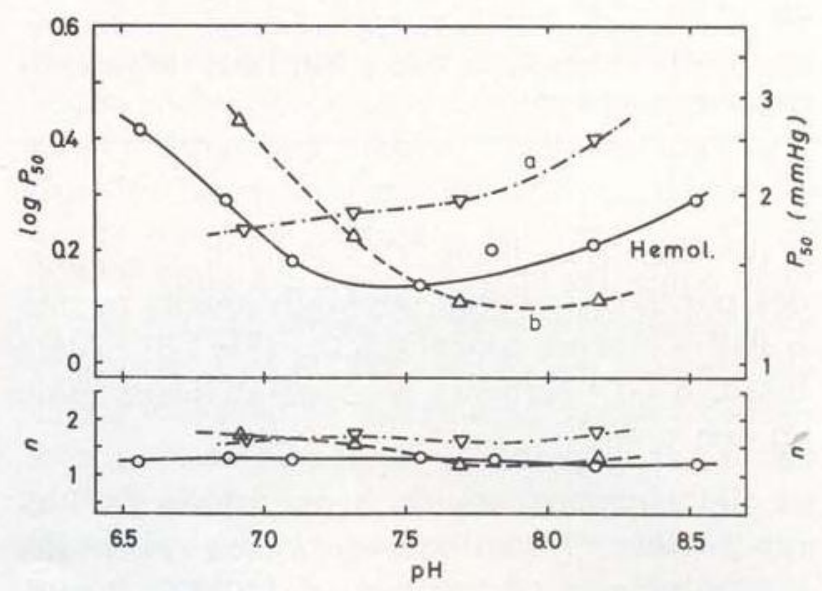

Fig. 2 - Dependência de $\mathrm{pH}$ do $\mathrm{P}_{50}$ e valores de $\mathbf{n}$ de hemoglobinas fracionadas de Pterygoplichthys medida em tampões Tris e Bis Tris, $I=0,05$ a $25^{\circ} \mathrm{C}$, hemolisado, 0,33 mM Hb; $\Delta$, fração a (cf. Fig. 4B), $0,06 \mathrm{mM} \mathrm{Hb} ; \nabla$, fração b, $0,08 \mathrm{mM} \mathrm{Hb}$. 

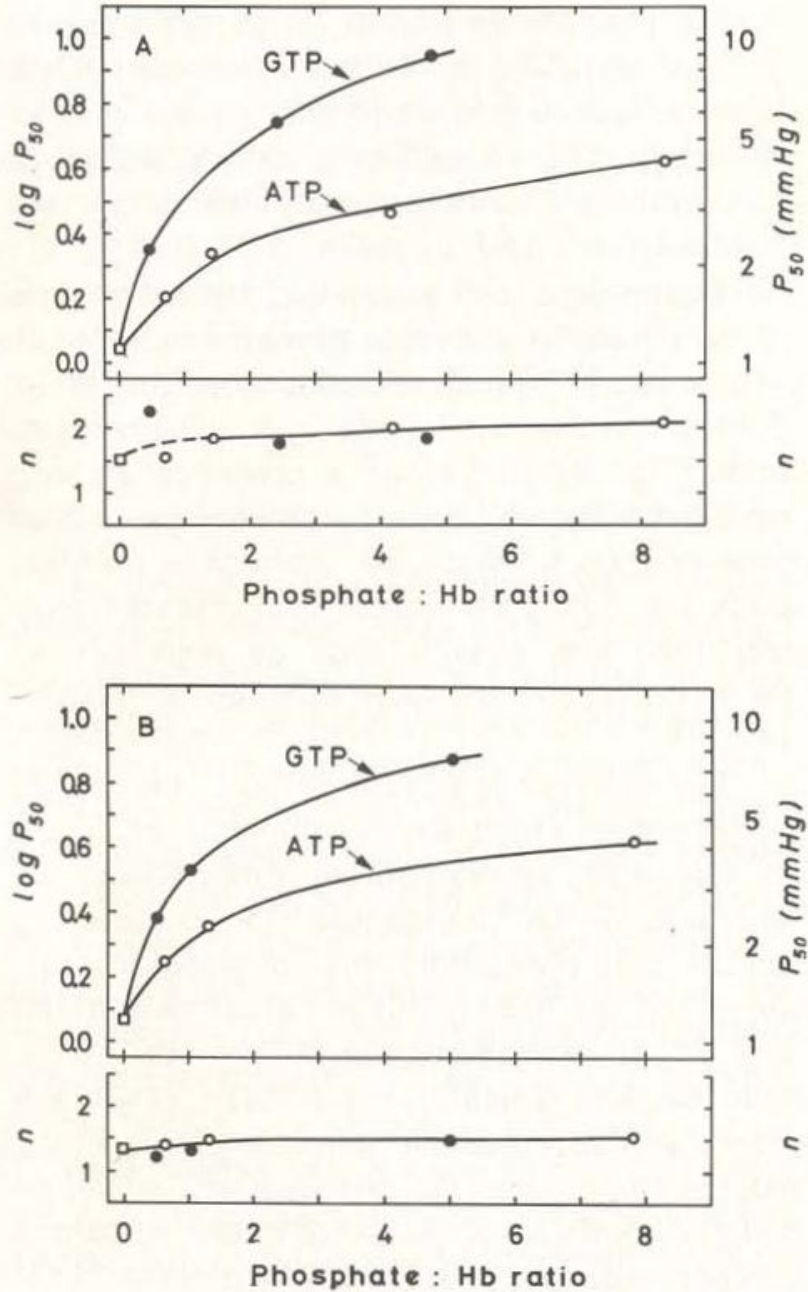

Fig. 3a e b - Efeitos de ATP (O) e GTP (•) sobre $P_{50}$ e valores de $\mathbf{n}$ de hemolisados fracionados de (A) Hypostomus e (B) Pterygoplichthys medidos a $25^{\circ} \mathrm{C}$ em tampão Tris, $\mathrm{pH} 7,30, I=0,05$, concentração de hemoglobina de 0,15 e $0,27 \mathrm{mM}$, (tetrâmero) respectivamente.

e GTP; como no lisado GTP diminui as afinidades por $\mathrm{O}_{2}$ duas vezes tão efetivamente quanto o ATP à mesma concentração, (Fig. 5). Além disso, o GTP aumenta a cooperatividade mais do que o ATP.

Os componentes de hemoglobina de Pterygoplichthys foram posteriormente resolvidos e estudados por Brunori et al. (1978). A comparação dos dois grupos de resultados indicam que as propriedades da hemoglobina da fração "a" (Fig. "4b) corresponde intimamente às do componente I de hemoglobina de Pterygoplichthys isolado por Brunori et al. (1978) e que a fração "b" provavelmente contém o componente IV de Brunori et al. (1978) e componentes adicionais com propriedades mais parecidas com as do componente I (cf. Brunori et al. (1978) para pormenores posteriores).

\section{DISCUSSÃo}

Os dados presente demonstram que uma alta sensibilidade ao fosíato da afinidade por $\mathrm{O}_{2}$ das hemoglobinas livres de cofatores de Hypostomus e Pterygoplichthys provêm a base para a resposta adaptativa de todo o sangue a águas hipóxicas e conseqüente aeróbia. A maior sensibilidade de afinidade por $\mathrm{O}_{2}$ das hemoglobinas a GTP do que a ATP é de interesse, considerando que durante a hipóxia a GTP decresce mais do que ATP (Weber et al.,
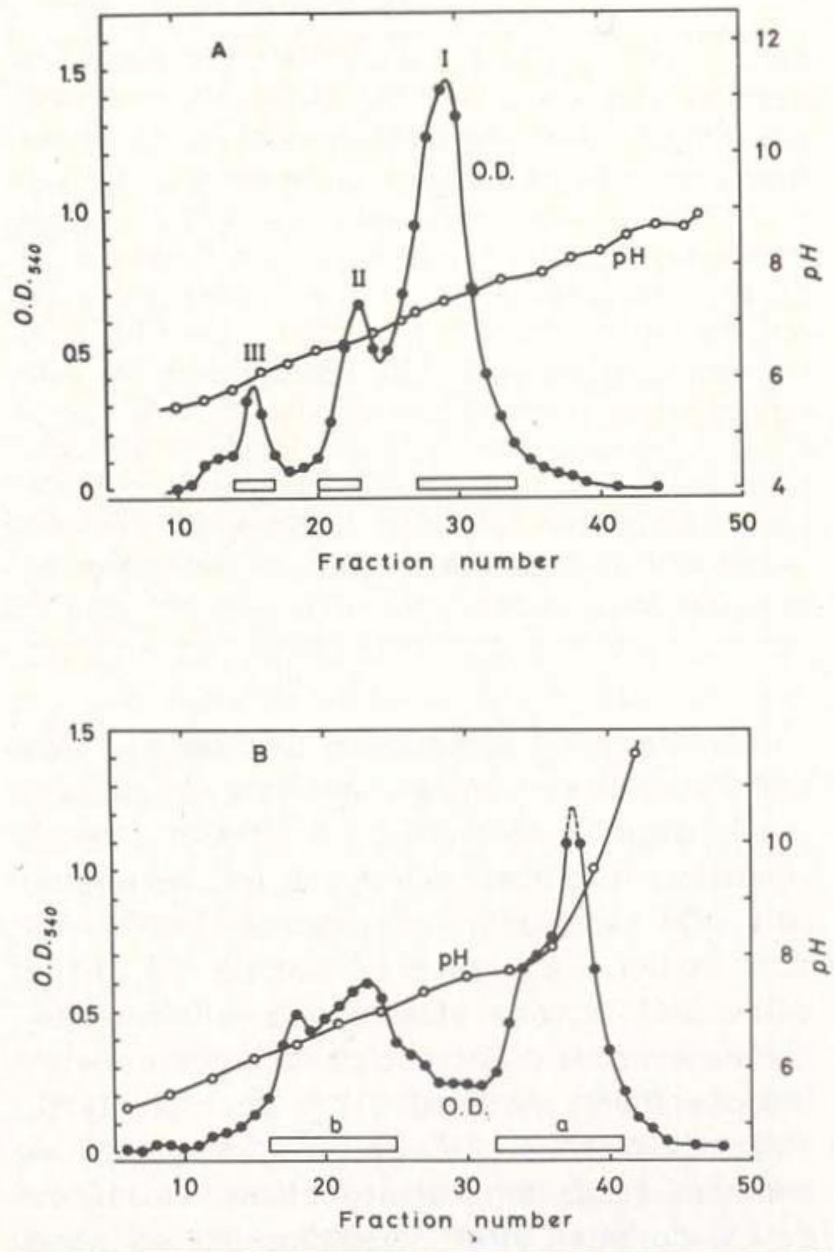

Fig. 4a e b-Focalização isoelétrica de carboxi derivados de hemoglobina de (A) Hypostomus e (B) Pterygoplichthys. densidades óticas a $540 \mathrm{mM}$; O, valores de $\mathrm{pH}$ a $5^{\circ} \mathrm{C}$ de fraçōes de $1,6 \mathrm{ml}$ coletadas da coluna. 
(1978). Assim, a GTP mais que a ATP é primariamente envolvido na adaptação do sangue $P_{50}$ ao modo de respiração. Estas observações são similares a dados prévios sobre hemoglobinas de enguias e peixes pulmonados onde a GTP é o principal fator de adaptação da afinidade por $\mathrm{O}_{2}$ a águas hipóxicas e estivação respectivamente (Weber et al., 1975; Johansen et al., 1975) .

Há diversos fatores a que se poderia atribuir as diferenças entre as propriedades de oxigenação das soluções de hemoglobina aqul citadas, e as do sangue total. Os cofatores não apenas incrementam $P_{50}$, mas também o aparente efeito Bohr de acordo com a aumentada ligação dos poliânions pela hemoglobina a baixo pH (cf. Benesch \& Benesch, 1974), explicando em parte os maiores fatores Bohr no sangue $(\Phi=-0,18$ e 0,32 entre $\mathrm{pH} 7,5$ e 8,0 para respiração de Hypostomus aérea e na água respectivamente) do que no hemolisado fracionado à $\mathrm{pH}$ similar $(\Phi \sim 0,0$; cf. Fig. 1) . Mesmo na presença de nucleosídio trifosfato saturante o $P_{50}$ de soluções de hemoglobinas, entretanto, são consideravelmente mais baixos do que os do sangue. Para Hypostomus a $30^{\circ} \mathrm{C}$ e pH 7,4 os valores $P_{50}$ sangüíneos são cerca de 15 e $22 \mathrm{~mm} \mathrm{Hg}$ para espécimes aclimatados e hipóxia e normoxia (Weber et al., 1978). Outros três importantes fatores do que interação alostérica de hemoglobina e cofatores, têm que ser considerados. Primeiramente, as concentrações de hemoglobina dentro dos glóbulos vermelhos de bagre (ca. $5 \mathrm{mM}$ ) são mais altas do que as das quais as propriedades da hemoglobina em solução podem ser medidas. Enquanto a afinidade de $\mathrm{O}_{2}$ de hemoglobina decresce com concentrações crescentes, este efeito é muito mais pronunciado na presença de fosfatos orgânicos mesmo à razão molar constante para hemoglobina (cf. Rorth, 1973) .

Em segundo lugar, o pH intracelular de glóbulos vermelhos de peixe são significativamente mais baixos do que aqueles medidos no sangue total. A um plasma de $\mathrm{pH} 7,4,0 \mathrm{pH}$ intracelular em enguias é cerca de 0,3 a 0,6 unidades de $\mathrm{pH}$ mais baixas dependendo do NTP do glóbulo vermelho. (Wood \& Johansen, 1973). Assim, o efeito Bohr medido a pH 7,0 a 7,5 no sangue total deve ser comparado com o de uma faixa mais baixa de $\mathrm{pH}$ no caso de

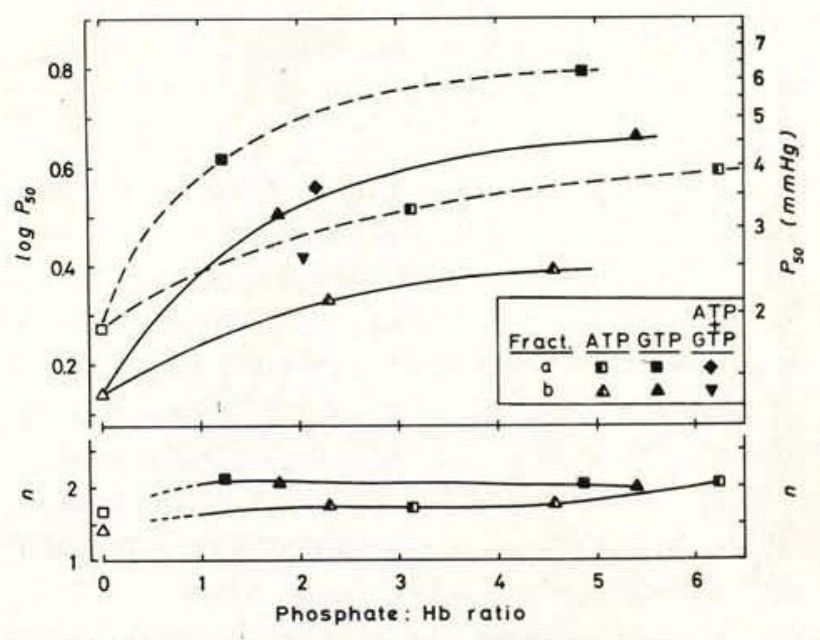

Fig. 5 - Efeitos de $\operatorname{ATP}(\boldsymbol{D}, \boldsymbol{\Delta}), \operatorname{GTP}(\boldsymbol{\mathbf { a }}, \boldsymbol{\Delta})$ e de ATP+GTP (,$\nabla$; plotados a concentrações totais de fosfato) sobre frações de hemoglobinas a (quadrados) e b (triângulos) isoladas de hemolisado de Pterygoplichthys (cf. Fig. 4B) por focalização isoelétrica, medidos a $25^{\circ} \mathrm{C}$ em tampão Tris, $I=0,05, p H=7,50$. Concentrações hemoglobínicas 0,06 e $0,08 \mathrm{mM}$ nas frações a e b, respectivamente.

soluçōes de hemoglobina. Por último, $\mathrm{O}^{\mathrm{CO}_{2}}$ presente in vivo diminuirá a afinidade $\mathrm{O}_{2}$ mais a $\mathrm{pH}$ alto do que baixo (o qual decrescerá o aparente efeito Bohr) pois o $\mathrm{CO}_{2}$ compete com o fosfato por um sítio de ligação comum na cadeia $\beta$ da hemoglobina tetrâmera de vertebrado (cf. Rorth, 1973).

Os cofatores fosfatos aumentam os valores $n$ das hemoglobinas de bagre (Figs. 1, $3 \mathrm{e}$ 5). $\mathrm{Na}$ presença de adequadas diferenças de $\mathrm{pO}_{2}$ artériovenosas, isto significa uma liberação mais eficiente do pigmento quando o sangue está nos tecidos. Pode também ser significativo que, com o mesmo $P_{50}$, um incremento em $n$ aumentará a saturação de $\mathrm{O}_{2}$ de hemoglobina a altos valores de $\mathrm{pO}_{2}$ como ocorre nas guelras em águas bem oxigenadas. Consequentemente, o incremento em $n$ associado com a elevação de fosfatos de glóbulos vermeIhos poderia aumentar a liberação de $\mathrm{O}_{2}$ nos tecidos sem o correspondente decréscimo na liberação de $\mathrm{O}_{2}$ nas guelras. Entretanto, um maior valor de $n$ não aumentará necessariamente a liberação de $\mathrm{O}_{2}$, a menos que as tensões venosas de $\mathrm{O}_{2}$ permaneçam abaixo do valor de $P_{50}$ do sangue, ex., através de um concomitante decréscimo na afinidade de $\mathrm{O}_{2}$ (Wood \& Lenfant, 1976) e uma exata avaliação 
da importância adaptativa das mudanças no $n$ devem esperar medidas de tensão sangüínea de $\mathrm{O}_{2}$ in vivo.

Os dados presentes mostram que em ambos os bagres, todos os componentes de hemoglobinas estudados estão envolvidos na modulação induzida por fosfato da afinidade de $\mathrm{O}_{2}$ dos glóblos vermelhos. Isto contrasta com a enguia européia onde o efeito alostérico de fosfatos sobre $P_{50}$ é quase inteiramente atribuível ao efeito de GTP sobre um único componente hemoglobínico eletroforeticamente catódico (Weber et al., 1975) .

A heterogeneidade de cargas caracteriza as hemoglobinas de muitos peixes e outros vertebrados inferiores. Enquanto os diferentes componentes hemoglobínicos em peixe algo menos ativo mostra sensibilidade similares de $\mathrm{P}_{50}$ ("normal") a $\mathrm{pH}$ e temperatura (cf. o sugador Catostomus insignis, a carpa, um ciclídio do Rio Grande e linguado norte-europeu Power, 1972; Gillen \& Riggs, 1972, 1973a; Weber \& De Wilde, 1976), outros peixes como salmão, truta, enguias européias, norte-americanas e japonesas, e o sugador Catostomus clarkii de águas correntes, possuem componentes hemoglobínicos adicionais que migram catodicamente sob condiçōes eletroforéticos normais, e possuem reduzidas ou revertidas sensibilidade de $\mathrm{pH}$ (Hashimoto et al. 1960; Binotti et al., 1971; Gillen \& Riggs, 1973b; Yamaguchi et al., 1963; Weber et al. 1975; Powers, 1972; Powers \& Edmundson, 1972). Nas hemoglobinas catódicas de truta e Cotostomus clarkii, a ausência de um efeito Bohr "alcalino" normal correlaciona-se com a descoberta (Powers \& Edmunson, 1972; Brunori et al., 1973) de que o resíduo histidínico carbóxi-terminal da cadeia $\beta$ e o grupo $\propto$-amino da cadeia $\propto$ los quais juntos são responsáveis por cerca de $75 \%$ do efeito Bohr em hemoglobina de mamíferos-Kilmartin \& Wootton, 1970) são substituídos e bloqueados respectivamente.

Tem sido postulado que as hemoglobinas catódicas de peixe asseguram a ligação de $\mathrm{O}_{2}$ no sangue sob condições de baixo ambiente de $\mathrm{pO}_{2}$ e pH (Hashimoto et al., 1960) ou durante acidose metabólica induzida pela atividade (Por wers, 1972; Powers \& Edmundson, 1972). A ocorrência de um componente hemoglobínico catódico com efeito Bohr revertido em
Pterygoplichthys mas não em Hypostomus, a despeito de seus hábitos e habitat similares e sua íntima relação filogenética, entretanto, provê evidência contra tais relações entre habitat e variação de hemoglobina no peixe.

\section{AGRADECIMENTOS}

Esta pesquisa foi financiada pelo National Science Foundation Grant PCM 75-06451 para o barco de pesquisas "Alpha Helix", pelo Danish Natural Science Research Council, Grant 511-6734 (R.E.W.) e o U.S. National Institute of Health Grant HL-18026 (S.C.W.) . Agradecimentos são devidos ao Governo Brasileiro pela permissão para efetivarmos a expedição no rio Amazonas.

\section{SUMMARY}

Oxygen equilibria of Hypostomus and Pterygoplichthys hemoglobins and their sensitivities to the erythrocytic nucleoside triphosphates (NTP), ATP and guanosine triphosphate (GTP) are studied to investigate the mechanisms by which blood adapts to air-and water-breathing. Hemoglobins of both species are heterogeneous. All hemoglobin fractions isolated by iso-electric focusing reveal a high sensitivity to NTP, but GTP depresses $\mathrm{O}_{2}$ affinity about twice as effectively as ATP. A cathodic hemoglobin component with a reversed Bohr effect was found in Pterygoplichthys but not in Hypostomus. The data are discussed in relation to the in vivo cofactor modulation of blood $\mathrm{O}_{2}$ affinity and the adaptive significance of functional heterogeneity of fish hemoglobins.

\section{BIBLIOGRAFIA}

BENESCH, R.E. \& BENESCH, R.

1974 - The mechanism of interaction of red cell organic phosphates with hemoglobin. In: Advances in Protein Chemistry, 28. (ed.: ANFINSEN, C.B. et al.) New York, Academic Press.

Binotti, I; GIOvenco, S.; GLARdina, B.; ANTONINI, E.; BRUNORI, M. \& WYMAN, J.

1971 - Studies on the functional properties of fish haemoglobins - II. The oxygen equilibrium of isolated haemoglobin components from trout blood. Archs. Biochem. Biophys., 142:274-280.

BRUNori, M.; Bonaventura, J.; Bonaventura, C.; GIARDINA, B.; BossA, F. \& ANTONINI, E.

1973 - Hemoglobins from trout: Structural and functional properties. Molec. Cell. Biochem, 1:189-196. 
BRUNORI, M.; BONAVENTURA, J.; Focesi JR., A.; GALDAMES-PORTUS, M.I. \& WILSON, M.T.

1978 - Separação e caracterização dos componentes de hemoglobina de Pterygoplichthys patdalis, o acaribodó. Acta Amazonica. 8(4): Suplemento. (Este volume).

FYHN, U.E.H.; FYhN, H.J.; DAVIS, B.J.; POWERS, D.A.; FINK, W.L. \& GARLICK, R.L.

1978 - Heterogeneidade de hemoglobina nos peixes da Amazônia. Acta Amazonica $8(4)$ : Suplemento. (Este volume).

GILLEN, R.G. \& RigGs, A.

1972 - Structure and function of the hemoglobins of the carp, Cyprinus carpio. J. Biol. Chem., 247:6039-6046.

$1973 \mathrm{a}$ - The hemoglobina of a fresh water teleost, Cichlasoma cyanoguttatum (Baird and Girard) - Subunit structure and oxygen equilibria of the isolated components. Archs. Biochem. Biophys., 154:348-359.

$1973 \mathrm{~b}$ - Structure and function of the isolated hemoglobins of the american eel, Anguilla rostrata. J. Biol. Chem., 248 : 1961-1969.

Hashimoto, K.; Yamaguchi, Y. \& MatsuUra, F.

1960 - Comparative studies on two hemoglobins of salmon - IV. Oxygen dissociation curve. Bull. Jap. Soc. Scient. Fish., 26:827-834.

JohaNSEN, K.; LyKKeboe, G.; Weber, R.E. \& MALOT, G.M.O.

1976 - Respiratory properties of blood in awabe and estivating lungfish, Protopterus amphibius. Respir. Physiol., 27:335-345.

KILMARTIN, J.V. \& WOOTTON, J.F.

1970 - Inhibition of Bohr effect after removal of C - Terminal histidines from haemoglobin B - chains. Nature, 228:766-767.

Niesel, W. \& Thews, G.

1961 - Ein neues Verfahren zur schnellen und genauen Aufnalme der Sauerstoffbindungskurve des Blutes und konzentrierter Hämoproteidlosnungen Pflügers Arch. ges Physiol.

POWERS, D.A.

$$
\begin{aligned}
& 1972 \text { - Hemoglobin adaptation for fast and } \\
& \text { slow water habitats in sympatric }
\end{aligned}
$$

catostomid fishes. Science N. Y., 177 : 360-362.

POWers, D.A. \& EDMUNDSON, A.B.

1972 - Multiple hemoglobins of catostomid fish - I. Isolation and characterization of the isohemoglobins from Catosostomus. J. Biol. Chem., 247:6686-6693.

REINITZ, G.L.

1976 - Comparison of techniques for stabilizing hemoglobins of rainbow trout (Salmo gairdneri) daring frozen sotrage. Comp. Biochem. Physiol., 55B : 357-358.

RORTH, M.

1973 - Hemoglobin interactions and red cell metabolism. Denmark, A. Backhaus \& H. J. Sorensen Printers, pp. 1-104.

WEBER, R.E. \& DE WILDE, J.A.M.

1976 - Multiple haemoglobins in plaice and flounder and their functional properties. Comp. Biochem. Physiol., 54B : 433-437.

Weber, R.E.; LYKKeboe, G. \& Johanseñ, K.

1975 - Biochemical aspects of the adaptation of hemoglobin-oxygen affinity of eels to hypoxia. Life Sciences, 17:1345-1350.

WebER, R.E.; WoOD, S.C. \& DAvis, B.J.

1978 - Aclimatação de peixe de respiração aérea facultativa a água hypóxica: afinidade pelo oxigênio do sangue e agentes alostéricos. Acta Amazonica 8(4): Suplemento. (Este volume).

WoOd, S.C. \& JohaNSEN, K.

1973 - Organic phosphate metabolism in nucleated red cells: Influence of hypoxia on eel $\mathrm{HbO}_{2}$ affinity. Neth. J. Sea Res., 7:328-338.

WOOD, S.C. \& LENFANT, C.J.M.

1976 - Respiration: Mechanics. Control and Gas Exchange. In: Biology of Reptilia (Ed. Gans. C. \& Dawson, W.R.) New York, Academic Press. 5 : 225-274.

WOOD, S.C.; Weber, R.E. \& DAVIS, B.J.

1978 - Efeitos da respiração aérea sobre o balanço ácido-base no cascudo Hypostomus sp. Acta Amazonica 8(4) : Suplemento. (Este volume).

YАMAGUCHI, K.; КоснтҮАМА, Y.; НиSHIMOTо, K. \& MATSUURA, F.

1963 - Studies on two hemoglobins of loach - II. Oxygen dissociation curve. Bull. Jap. Soc. Scient. Fish., 29:180-188 . 